\title{
INVERSION THEOREM FOR NONCONVEX MULTIFUNCTIONS
}

\author{
Hui HUANG
}

Abstract. Using the techniques of variational analysis, we extend the inversion theorem of Robinson for convex multifunctions to $\gamma$-paraconvex multifunctions, preinvex multifunctions and strongly convex multifunctions, respectively. The results are used to derive upper bounds on the distance from an approximate solution to the solution set.

Mathematics subject classification (2010): 90C31, 90C25, 49J52.

Keywords and phrases: Inversion theorem, $\gamma$-paraconvex multifunction, preinvex multifunction, strongly convex multifunction, normed space.

\section{REFERENCES}

[1] D. Bhatia And A. Mehra, Lagrangian duality for preinvex set-valued functions, J. Math. Anal Appl., 214 (1997), 599-612.

[2] F. H. Clar Ke, Optimization and Nonsmooth Analysis, John Wiley \& Sons, New York, 1983.

[3] H. HUANG, Global error bounds with exponents for multifunctions with set constraints, Communications in Contemporary Mathematics, 12 (2010), 417-435.

[4] A. Jourani, Open mapping theorem and inversion theorem for $\gamma$-paraconvex multivalued mappings and applications, Studia Mathematica, 117, 2 (1996), 123-136.

[5] W. Li AND I. Singer, Global error bounds for convex multifunctions and applications, Math. Oper. Res., 23 (1998), 443-462.

[6] G. H. Lin AND M. Fukushima, Some exact penalty results for nonlinear programs and mathematical programs with equilibrium constraints, J. Optim. Theorey Appl. 118 (2003), 67-80.

[7] S. M. Robinson, Regularity and stability for convex multivalued functions, Math. Oper. Res., 1 (1976), 130-143.

[8] J. S. PANG, Error bounds in mathematical programming, Math. Programming (ser. B), 79 (1997), 299-332.

[9] B. H. SHENG AND S. Y. LIU, Kuhn Tucker condition and Wolfe duality of preinvex set-valued optimization, Appl. Math. Mech., 27 (2006), 1655-1664.

[10] S. RolewiCZ, on $\gamma$-paraconvex multifunctions, Math. Japon., 24 (1979), 293-300.

[11] C. URSESCU, Multifunctions with convex closed graph, Czechoslovak Math. J., 7 (1975), 438-441.

[12] T. WeIR And B. Mond, Preinvex functions in multiple-objective optimalization, J. Math. Anal. Appl., 136 (1988), 29-38.

[13] X. Y. ZHENG, Error bounds for set inclusion, Science in China (ser.A), 46 (2003), 750-763. 